\title{
Preparing Biochars from Cow Hair Waste Produced in a Tannery for Dye Wastewater Treatment
}

\author{
Jinzhi Song ${ }^{1}$, Yun $\mathrm{Li}^{2}{ }^{\circledR}$, Yang Wang ${ }^{3}$, Lei Zhong ${ }^{1}$, Yang Liu ${ }^{1}$, Xinyue Sun ${ }^{1}$, Bo He ${ }^{1}$, Yanchun $\mathrm{Li}^{1, *}$ \\ and Shan Cao ${ }^{1, *(1)}$ \\ 1 State Key Laboratory of Biobased Material and Green Papermaking, School of Light Industry and \\ Engineering, Qilu University of Technology (Shandong Academy of Sciences), Jinan 250353, China; \\ 1043118248@stu.qlu.edu.cn (J.S.); 1043118526@stu.qlu.edu.cn (L.Z.); 1043117266@stu.qlu.edu.cn (Y.L.); \\ 1043118034@stu.qlu.edu.cn (X.S.); 1043119079@stu.qlu.edu.cn (B.H.) \\ 2 College of Chemistry and Chemical Engineering, Yantai University, Yantai 264005, China; liyun@ytu.edu.cn \\ 3 College of Chemistry, Chemical Engineering and Materials Science, Shandong Normal University, Jinan \\ 250014, China; wangyang@sdnu.edu.cn \\ * Correspondence: lyc@qlu.edu.cn (Y.L.); cs1988@qlu.edu.cn (S.C.)
}

check for updates

Citation: Song, J.; Li, Y.; Wang, Y.; Zhong, L.; Liu, Y.; Sun, X.; He, B.;

Li, Y.; Cao, S. Preparing Biochars from Cow Hair Waste Produced in a

Tannery for Dye Wastewater

Treatment. Materials 2021, 14, 1690.

https://doi.org/10.3390/ma14071690

Academic Editors:

Dorota Kołodyńska,

Teofil Jesionowski and

Polycarpos Falaras

Received: 5 January 2021

Accepted: 20 March 2021

Published: 30 March 2021

Publisher's Note: MDPI stays neutral with regard to jurisdictional claims in published maps and institutional affiliations.

Copyright: (c) 2021 by the authors. Licensee MDPI, Basel, Switzerland. This article is an open access article distributed under the terms and conditions of the Creative Commons Attribution (CC BY) license (https:/ / creativecommons.org/licenses/by/ $4.0 /)$.

\begin{abstract}
A large amount of cow hair solid waste is produced in leather production, and a reasonable treatment should be developed to reduce the pollution. In this study, cow hair waste was utilized as the carbon precursor, and $\mathrm{N}_{2}$ was determined to be the most appropriate atmosphere for biochar preparation. We performed a comparison of the properties of biochars that were prepared with different methods, including direct pyrolysis, $\mathrm{KOH}$ activation, and the $\mathrm{MgO}$ template method. The characterization results show that the highest specific surface area reaches $1753.075 \mathrm{~m}^{2} / \mathrm{g}$. Subsequently, the keratin that was extracted from cow hair and purified was used to prepare a biochar with the $\mathrm{MgO}$ template method, obtaining an orderly sponge structure. The biochar from cow hair waste was further used to absorb direct blue dye wastewater, and its adsorption capacity reached $1477 \mathrm{mg} / \mathrm{g}$ after $10 \mathrm{~h}$ with a high efficiency of regeneration. This study successfully utilized keratin-containing hair waste and provides a new source for synthesizing carbon materials for dye wastewater treatment.
\end{abstract}

Keywords: biochar; cow hair waste; keratin; high specific surface area; dye adsorption

\section{Introduction}

In leather production, a large amount of solid waste is produced. One of the main components of the waste is cow hair. Every ton of salt-wet cowhide can produce around $85 \mathrm{~kg}$ of waste hair [1]. Compared to wool, cow hairs are particularly difficult to apply in the textile industry due to their short length. The accumulation of large quantities of hair waste causes a huge waste of resources and deterioration of the environment, and it should be solved urgently. This hair waste is mainly composed of keratin, which is difficult to naturally degrade, and contains small amounts of lipids and minerals [2]. Only a few studies have paid attention to the recovery and reuse of cow hair waste, resulting in a huge waste of keratin resources. The keratin resources should be utilized for environmental benefit and economic value. Therefore, it is of great significance to find an effective method for the disposal of cow hair waste.

In recent years, bio-solid waste has been considered to be a carbon precursor for the preparation of biochars [3]. Successful attempts have been made to convert keratinous waste from the food industry and breeding industry, including feathers [4], ox horns [5], and pig nails [6]. Owing to the unique microscopic morphology, high specific surface area, and diverse elemental composition of biochars, increasing attention has been paid to potential applications in adsorption [7], electro-catalysis [8], and electrodes [9]. Ren et al. used goat hairs to achieve $3 \mathrm{D}$ porous carbon materials that were doped with nitrogen, oxygen, 
and phosphorus [10]. Based on these studies, natural keratin can be applied as a carbon precursor to prepare porous biochars with high performance. However, compared with the keratinous solid waste from the breeding industry and food industry, the cow hair waste from tanneries contains more impurities. It may influence the biochar preparation process.

Natural biomaterials have a unique structure and special composition, which will have an obvious impact on the final structure of prepared porous carbon materials [11]. The keratin formed by polypeptide chains constitutes the three-dimensional network structure of the cow hair [12]. By carbonization, the original hair structure will endow the obtained biochar with a special structure as well as high carbon content [13]. In addition, the biochar is usually heteroatom-doped, such as nitrogen-, oxygen-, or sulfur-doped [14]. In order to obtain a biochar with a high specific surface area and a well-distributed pore size, activators such as $\mathrm{KOH}$ [15], $\mathrm{ZnCl}_{2}$ [16], $\mathrm{H}_{3} \mathrm{PO}_{4}$ [17], and $\mathrm{HNO}_{3}$ [18] can be used to improve the properties. $\mathrm{KOH}$ activation can be considered because of its short activation cycle, simple operation, and excellent activation effect [19], and template methods may improve the orderliness of the mesoporous structure [20]. The biochar, which possesses abundant surface functional groups and a high specific surface area, may be favorable in application for adsorbing water contaminants [21].

In this study, the properties of cow hair waste produced in leather production are analyzed, and the original waste and keratin extracted from the waste are both used to prepare porous biochars. The influence of different carbonization atmospheres, including $\mathrm{N}_{2}$, $\mathrm{Ar}$, and air atmospheres, on the properties of the biochar are explored for optimization, and $\mathrm{KOH}$ activation and the $\mathrm{MgO}$ template method are applied for further improving the properties. The control strategies that can affect the performance of biochar are analyzed and summarized. Then, the obtained biochar is used to treat direct blue dye wastewater. The adsorption ability and the regeneration effect are observed and evaluated. This study provides an effective method for turning hair waste into biochar and applying it for dye adsorption.

\section{Materials and Methods}

\subsection{Materials}

The cow hair waste and the direct blue dye (DB) were of industrial grade and collected from the hair-saving unhairing process in Baoen Leather Industry Co., Ltd. (Zibo, China). The WB600 keratinase was obtained by Cao's method [22]. The granular activated carbon (AC) was of analytical grade and purchased from Sinopharm Group Chemical Reagent Co. Ltd. (Shanghai, China). Other reagents were of analytical grade and purchased from Tianjin Damao Chemical Reagent Factory (Tianjin, China).

\subsection{Characterization of Cow Hair Waste}

The cow hair waste was washed with distilled water $(1 / 10, v / v) 3$ times and dried at $80^{\circ} \mathrm{C}$ until the weight was constant. The structure was observed by field emission scanning electron microscopy (FESEM; s4800, Hitachi, Tokyo, Japan), and the elements in the cow hair wastes were analyzed by Energy Disperse Spectroscopy (EDS).

\subsection{Pre-Treatment of Cow Hairs}

The cow hairs were washed with distilled water and dried in an air-circulating oven at $80{ }^{\circ} \mathrm{C}$ for $6 \mathrm{~h}$. Then, the cow hairs were stored at $25^{\circ} \mathrm{C}$. The keratin was roughly extracted 10 times in $\mathrm{NaOH}$ solution $(0.1 \mathrm{~mol} / \mathrm{L}, w / w)$ at $100{ }^{\circ} \mathrm{C}$ for $2 \mathrm{~h}$, and then the hair was deeply degraded by WB600 keratinase at the concentration of $160 \mathrm{U} / \mathrm{mL}$ at $60{ }^{\circ} \mathrm{C}$ for $6 \mathrm{~h}$ until completely dissolved. Then, the hydrolysate solution was dialyzed overnight and freeze-dried for $72 \mathrm{~h}$. 


\subsection{Preparation of Cowhair-Based Char Materials}

\subsubsection{The Carbonization}

The cow hairs were carbonized directly. The cow-hair-based char materials (CCMs) were prepared in $\mathrm{N}_{2}$, Ar, and air atmospheres with a temperature-programmed heat treatment. The carbonization was processed at $350^{\circ} \mathrm{C}$ for $1 \mathrm{~h}$ at a rate of $5^{\circ} \mathrm{C} / \mathrm{min}$, and then the temperature was raised to $600{ }^{\circ} \mathrm{C}$ for $3 \mathrm{~h}$. The samples obtained merely by the carbonization are tagged as CCMc. The obtained CCMcs under different hot coflow conditions are labeled as $\mathrm{CCMc}-\mathrm{N} 2, \mathrm{CCMc}-\mathrm{Ar}$, and CCMc-Air, respectively.

\subsection{2. $\mathrm{KOH}$ Activation}

After cooldown, $1.00 \mathrm{~g}$ of CCMc were grinded and sifted. Then, they were mixed with $\mathrm{KOH}$ at a ratio of 1:4.5 $(w / w)$ in $30 \mathrm{~mL}$ of distilled water. The mixture was stirred at $45^{\circ} \mathrm{C}$ for $18 \mathrm{~h}$ and dried at $110{ }^{\circ} \mathrm{C}$. Subsequently, the samples were placed into the crucibles, and then were heated using the temperature-programmed heat treatment. The temperature rose continuously to $800^{\circ} \mathrm{C}$ for $3.5 \mathrm{~h}$ at a rate of $5^{\circ} \mathrm{C} / \mathrm{min}$. The cooled samples were washed with $\mathrm{HCl}(1.0 \mathrm{~mol} / \mathrm{L})$ to wipe off the residual $\mathrm{KOH}$ and then washed with deionized water until neutral $\mathrm{pH}$. Finally, the samples were dried at $80^{\circ} \mathrm{C}$ for $24 \mathrm{~h}$. The finished CCMs are defined as $\mathrm{CCMa}-\mathrm{N}_{2}, \mathrm{CCMa}-\mathrm{Ar}$, and CCMa-Air, respectively.

\subsection{Preparation of Char Materials by the Template Method}

The keratin powder was processed by the $\mathrm{MgO}$ template method [23]. The samples obtained using keratin were defined as keratin-based char material (KCM). A total of $30 \mathrm{~mL}$ of keratin solution $(200 \mathrm{~g} / \mathrm{L})$ was mixed with $6 \mathrm{~g}$ of magnesium citrate in $200 \mathrm{~mL}$ of distilled water with stirring, and $50 \mathrm{~mL}$ of $\mathrm{NaOH}(2.5 \mathrm{~mol} / \mathrm{L})$ was dripped into the mixture. Then, the sample was stirred at $70{ }^{\circ} \mathrm{C}$ for $3 \mathrm{~h}$ and dried at $100{ }^{\circ} \mathrm{C}$. The carbonization process was performed under a nitrogen atmosphere with a similar temperature-programmed heat treatment to that previously mentioned in the carbonization. Afterwards, the carbonized sample was pickled using $\mathrm{HCl}(10 \mathrm{wt} \%)$ to remove the $\mathrm{MgO}$ and washed with distilled water to $\mathrm{pH}$ 7. The sample was dried at $80^{\circ} \mathrm{C}$ and is defined as KCMc-T. In addition, the keratin powder was carbonized directly as a control sample, and this product is defined as $\mathrm{KCMc}-\mathrm{C}$. Afterwards, the $\mathrm{KCMc}-\mathrm{T}$ and $\mathrm{KCMc}-\mathrm{C}$ were treated with $\mathrm{KOH}$ activation, and the samples are defined as $\mathrm{KCMa}-\mathrm{T}$ and $\mathrm{KCMa}-\mathrm{C}$, respectively.

\subsection{Characterization of Porous Carbon Materials}

The morphology of CCMs and KCMs was observed with field emission scanning electron microscopy (FESEM; s4800, Hitachi, Tokyo, Japan) and transmission electron microscopy (TEM; JEM-2100, JEOL, Tokyo, Japan) [24]. An X-ray energy dispersive spectrometer (EDS) was used to perform the elemental analysis of samples under an SEM environment (Phenom pure plus, Phenom-World, Eindhoven, Netherlands). An X-ray diffractometer (XRD-6100, Shimadzu Corp., Kyoto, Japan) was used to analyze the crystalline structure of CCMs and KCMs. Raman spectroscopy (Horiban Jobin Yvon, LabRAM HR Evolution, Paris, France) was employed to investigate the Raman spectrum of the samples. FTIR spectra were collected on an IRAffinity-1S FTIR spectrometer (Shimadzu Corp., Kyoto, Japan) using the $\mathrm{KBr}$ pellet technique [15]. An ESCALABXi + X-ray photoelectron spectrometer (Thermo fisher technology co., LTD, Waltham, MA, USA) was used for elemental analysis. The specific surface area of the samples was evaluated by $\mathrm{N}_{2}$ absorption-desorption and the Brunauer-Emmett-Teller (BET) method using the Micromeritics Gemini 2380 (Micromeritics instrument Co., Norcross, GA, USA) surface area analyzer [25]. Before absorption measurements, the samples were degassed at $150{ }^{\circ} \mathrm{C}$ for $3 \mathrm{~h}$ in a vacuum. Then, the Barrett-Joyner-Halenda (BJH) theory method was used to determine the pore size distributions [26]. In addition, all the experiments were repeated at least three times. 


\subsection{Adsorption and Regeneration Experiments}

\subsubsection{Adsorption Experiment}

The conventional dosage of dye used in leather production is usually approximately $5 \%(w / w)$ of hide weight [27]. After dyeing, the dye concentration of wastewater is in the range of 10-50 g/L, which was referred to for designing the concentration of simulated direct blue dye wastewater. The AC is used for comparison. In addition, the saturated dye solution $(100 \mathrm{~g} / \mathrm{L})$ was used for exploring the highest adsorption ability of biochar. A total of $50 \mathrm{mg}$ of biochar was put into $10 \mathrm{~mL}$ dye solutions with different concentrations and shaken at $25{ }^{\circ} \mathrm{C}$. The maximum absorption wavelength of the direct blue dye was determined by UV detection at $567 \mathrm{~nm}$ [28]. The adsorption capacity at each moment was calculated according to Equation (1).

$$
Q_{t}=\frac{C_{o}-C_{t}}{M} \cdot V
$$

where $Q_{t}$ is the adsorption capacity at time $t(\mathrm{mg} / \mathrm{g}) ; C_{o}$ is the initial concentration of the direct blue dye $(\mathrm{mg} / \mathrm{L}) ; C_{t}$ is the ultimate concentration of the direct blue dye at time $t$ (mg/L); $M$ is the mass of the sample (g); and $V$ is the volume of the dye solution (L).

\subsubsection{Desorption and Regeneration Experiment}

After adsorption, the biochar was washed with $10 \mathrm{~mL}$ of a mixed solution of $\mathrm{HNO}_{3}$ $(0.5 \mathrm{~mol} / \mathrm{L})$ and $\mathrm{NaNO}_{3}(0.5 \mathrm{~mol} / \mathrm{L})$ at $80^{\circ} \mathrm{C}$ for $1 \mathrm{~h}$. Then, it continued to be washed until the supernatant was transparent. The washed biochar was dried at $40^{\circ} \mathrm{C}$ for $24 \mathrm{~h}$ and used for next round of adsorption. The adsorption experiment with a direct blue concentration of $50 \mathrm{mg} / \mathrm{L}$ was performed with 5 cycles.

\section{Results}

\subsection{Properties Analysis of Cow Hair Waste}

The cow hair waste retained a relatively intact scale layer. After washing, $\mathrm{Na}_{2} \mathrm{~S}$ and other reagents can be successfully removed. The C, N, and O elements are 53.96\%, 18.29\%, and $26.37 \%$ (Figure 1), respectively. The high $\mathrm{C}$ content is positive for preparing biochar. In addition, small amounts of S $(0.92 \%)$ and $\mathrm{Ca}(0.46 \%)$ were detected in the cow hair, which are due to the presence of disulfide bonds in the keratin and the use of lime in the liming process, respectively.

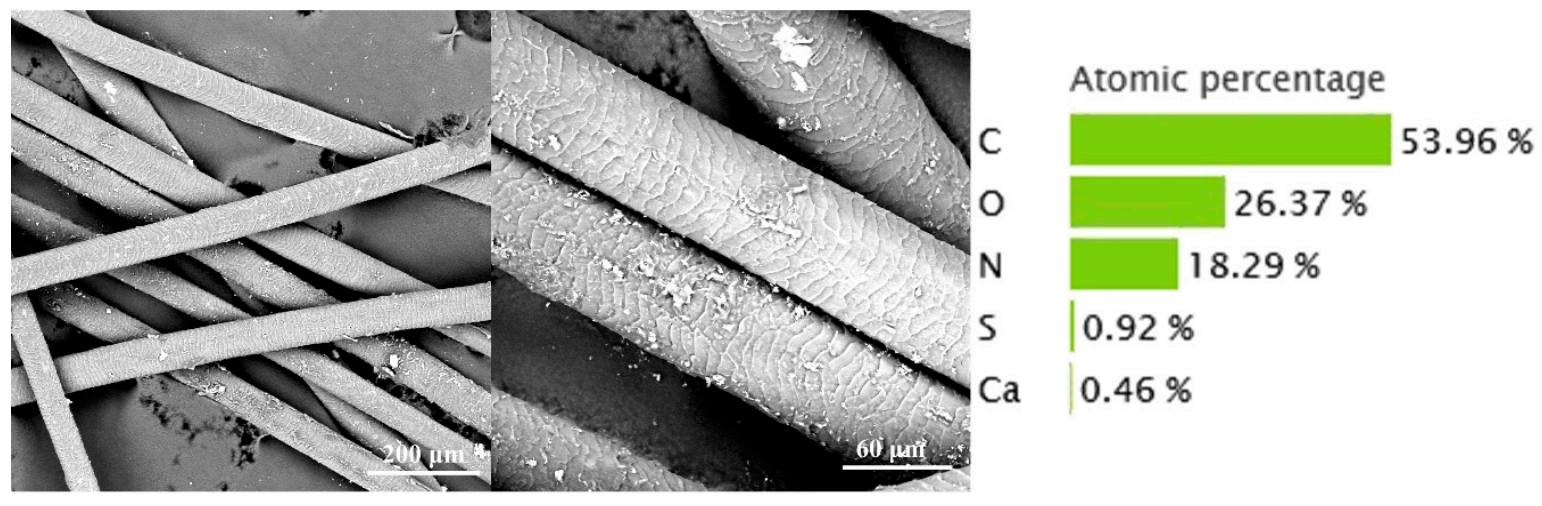

Figure 1. Image of hair waste.

\subsection{The Preparation of Biochars}

The flowchart of biochar preparation is described in Figure 2. Cow hair waste and keratin extracted from the waste were used for preparing biochars. The CCMcs (CCMc$\mathrm{N}_{2}$, CCMc-Ar, and CCMc-Air) were obtained by carbonization at $350-600{ }^{\circ} \mathrm{C}$ with $\mathrm{N}_{2}$, $\mathrm{Ar}$, and air, separately. After the $\mathrm{KOH}$ activation, the CCMa- $\mathrm{N}_{2}$ and $\mathrm{CCMa}-\mathrm{Ar}$ with a similar bread-like structure were obtained, and CCMa-Air has blocky nanostructures. In 
addition, the keratin was extracted from cow hairs by $\mathrm{NaOH}$ and $\mathrm{WB} 600$ enzymes. The keratin-based biochars were prepared with an $\mathrm{MgO}$ pretreatment in an $\mathrm{N}_{2}$ atmosphere. The simple carbonization causes the compacted structure of $\mathrm{KCMa}-\mathrm{C}$, whereas the $\mathrm{MgO}$ template treatment endows the $\mathrm{KCMa}-\mathrm{T}$ with an orderly porous sponge structure.
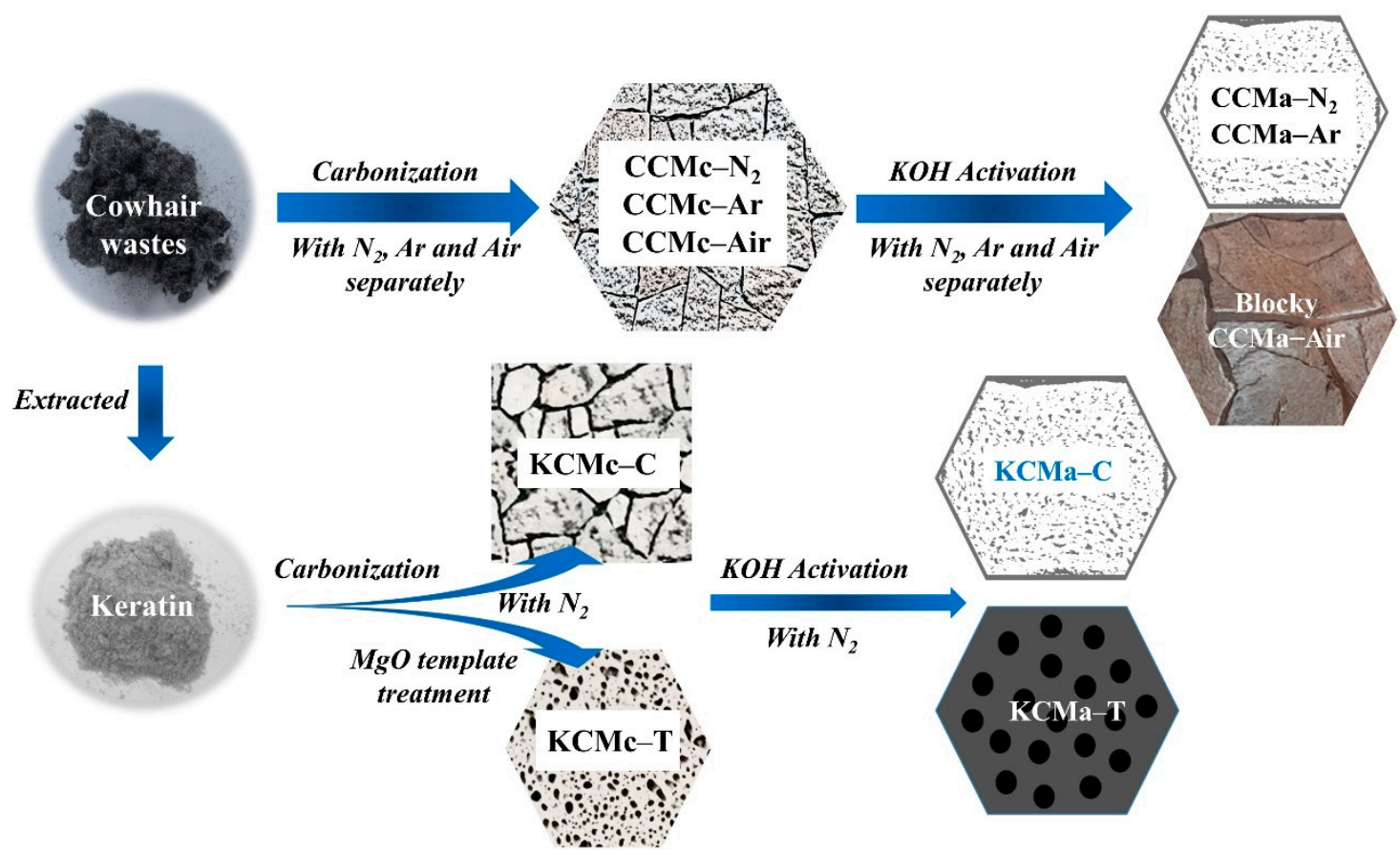

Figure 2. Flowchart of biochar preparation.

\subsection{Element Composition Analysis of Biochars}

Cow-hair-based biochars carbonized in $\mathrm{N}_{2}$, Ar, and air were observed and analyzed and the results are shown in Figure 3. It shows that the elemental composition of $C \mathrm{CMa}-\mathrm{N}_{2}$ and CCMa-Ar are similar and include $\mathrm{C}$ and $\mathrm{O}$. The $\mathrm{C}$ content of CCMa- $\mathrm{N}_{2}$ and $\mathrm{CCMa}-\mathrm{Ar}$ is $86.43 \%$ and $85 \%$, respectively, along with significant O-doping. The CCMa-Air includes high content of $\mathrm{O}(64.9 \%)$ and $\mathrm{Ca}(10.14 \%)$. It is known that hair waste usually contains some lime due to the dehair-liming process in leather production. Some $\mathrm{CaCO}_{3}$ is produced with the presence of $\mathrm{O}_{2}$ in air in carbonization, and it is difficult to fully remove it by $\mathrm{HCl}$ washing in $\mathrm{KOH}$ activation [29].

\subsection{Morphology Observation \\ 3.4.1. Morphology of CCMs}

The morphology of activated porous biochars was further observed by SEM. As shown in Figure 4, CCMa- $\mathrm{N}_{2}$ had a bread-like structure. The external structure of CCMa- $\mathrm{N}_{2}$ contained a smooth and flat outer shell (Figure 4(a2)), whereas its interior possessed a sponge structure (Figure 4(a1)). The internal pore diameters were irregular in the range of $5 \mathrm{~nm}$ (Figure 4(a3)) to $50 \mathrm{~nm}$ (Figure 4(a4)). In carbonization, the original hair structure is cracked. The tightly overlapping scales on the cow hair surface disappear at a high temperature to form the shell with a smooth surface. The organic components in the cow hair fibers are cracked, and $\mathrm{C}=\mathrm{O}$ and hydrogen-containing functional groups are volatilized to produce the larger pore structure in the carbon materials. The $\mathrm{KOH}$ activation produces the internal sponge structure, and the oxidation reaction of $\mathrm{KOH}$ produces $\mathrm{H}_{2}, \mathrm{CO}_{2}$, and $\mathrm{CO}$ gases, which cause the pore structure [30]. 


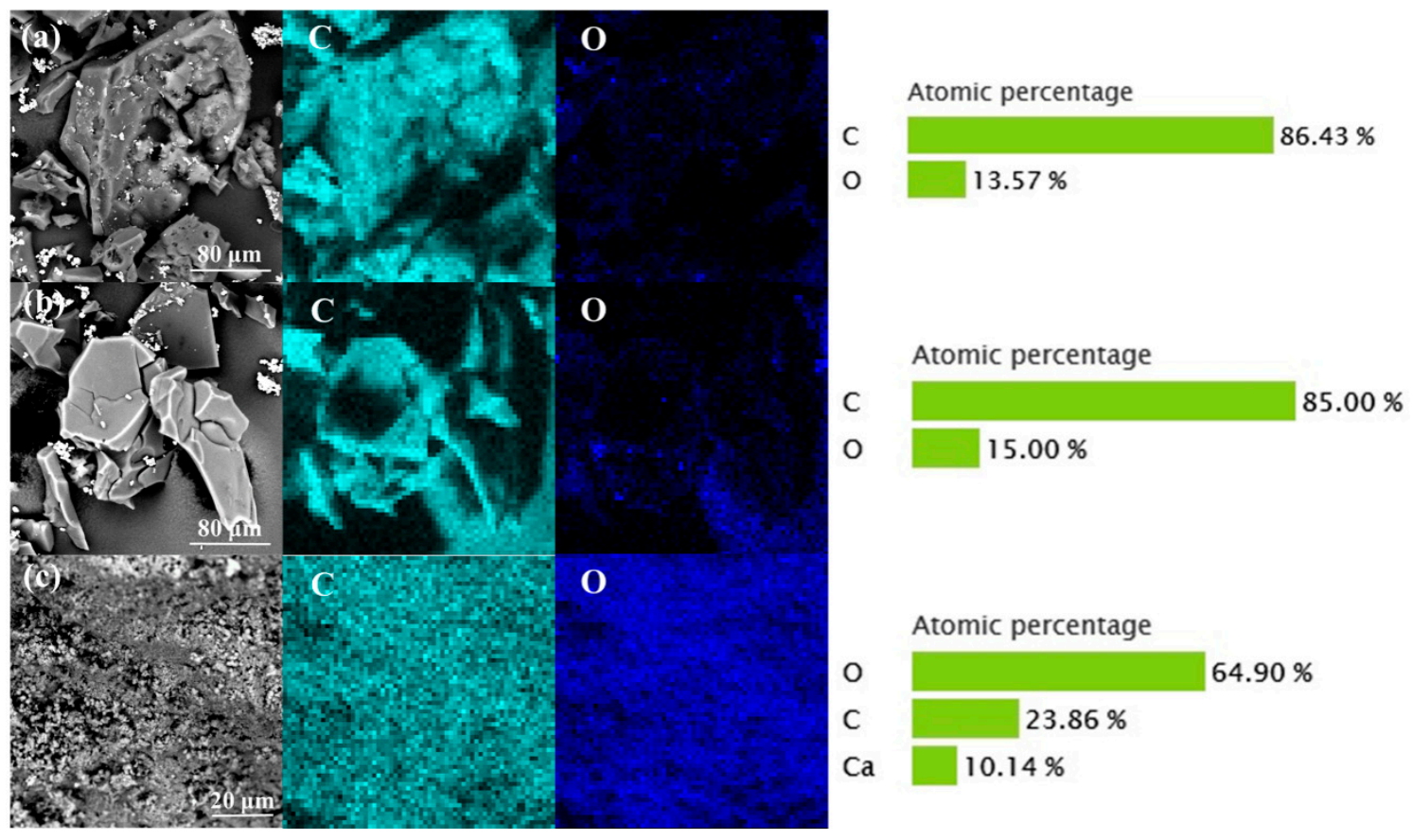

Figure 3. EDS of cow-hair-based char materials (CCMs). (a) CCMa-N $\mathrm{C}_{2}$ (b) CCMa-Ar; and (c) CCMa-Air.

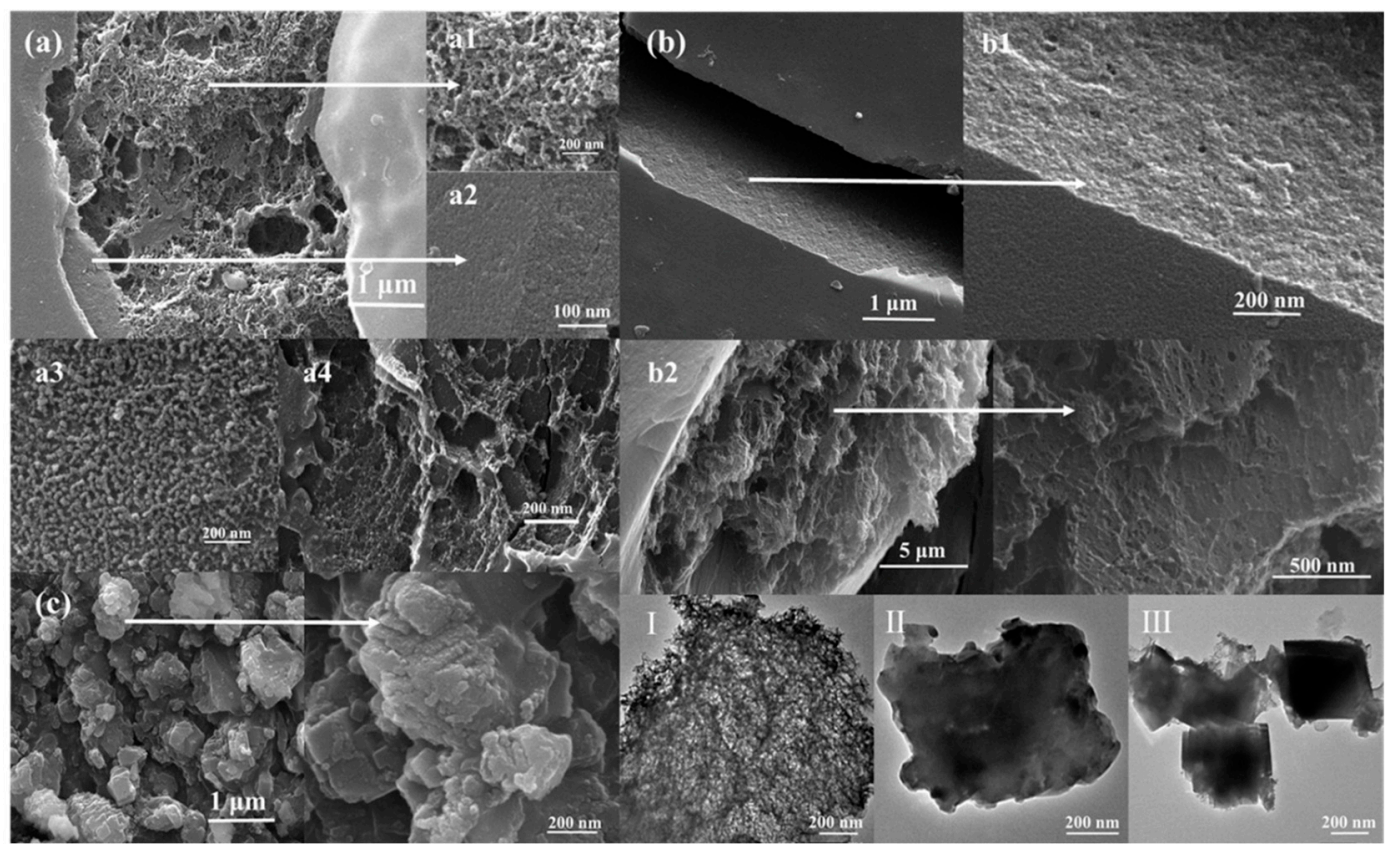

Figure 4. SEM (a-c) and TEM (I-III) images of (a) CCMa-N 2 ; (b) CCMa-Ar; (c) CCMa-Air; (I) CCMa-N 2 ; (II) CCMa-Ar, and (III) CCMa-Air.

With the Ar atmosphere, the interior structure of the obtained biochar (Figure 4(b2)) is similar to the structure of CCMa- $\mathrm{N}_{2}$. A large number of pores appear to form the sponge structure, which should be attributed to $\mathrm{KOH}$ activation, and it effectively improves the specific surface area of CCMa- $\mathrm{N}_{2}$ and CCMa-Ar [31]. As shown in Figure 4c, irregularly shaped particles were produced with the air atmosphere. With high-temperature pyrolysis, the reaction between $\mathrm{O}_{2}$ in air and keratin results in the loss of $\mathrm{C}$-containing functional groups of produced biochar, thereby contributing to the morphology with small and inconsistent size particles. By TEM spectra analysis (Figure 4I-III), the bread-like structures 
of CCMa- $\mathrm{N}_{2}$ and CCMa-Ar can be scrutinized with the abundance of interior pores, and the distribution of pores in CCMa-Ar is tighter than that in $C \mathrm{CMa}-\mathrm{N}_{2}$.

\subsubsection{Morphology of KCMs}

The KCMa-C is blocky with a large scale (Figure 5(a1)), and the $\mathrm{KOH}$ activation produces a number of pores in the surface (Figure 5(a2)). By the hydrolysis of hair to extract keratin, polypeptide chains with different molecular weights are generated, forming different scales of block structures (Figure 5(a3)). Obviously, the $\mathrm{MgO}$ template method leads to an orderly sponge structure (Figure $5 \mathrm{~b}$ ). After pyrolysis, $\mathrm{MgO}$ is removed, and the originally occupied position forms the mesoporous structure. In the TEM spectra (Figure 5I,II), the structure of $\mathrm{KCMa}-\mathrm{C}$ is more compacted (Figure $5 \mathrm{I}$ ). A number of mesopores appear by the $\mathrm{MgO}$ template method in KCMa-T (Figure 5II).

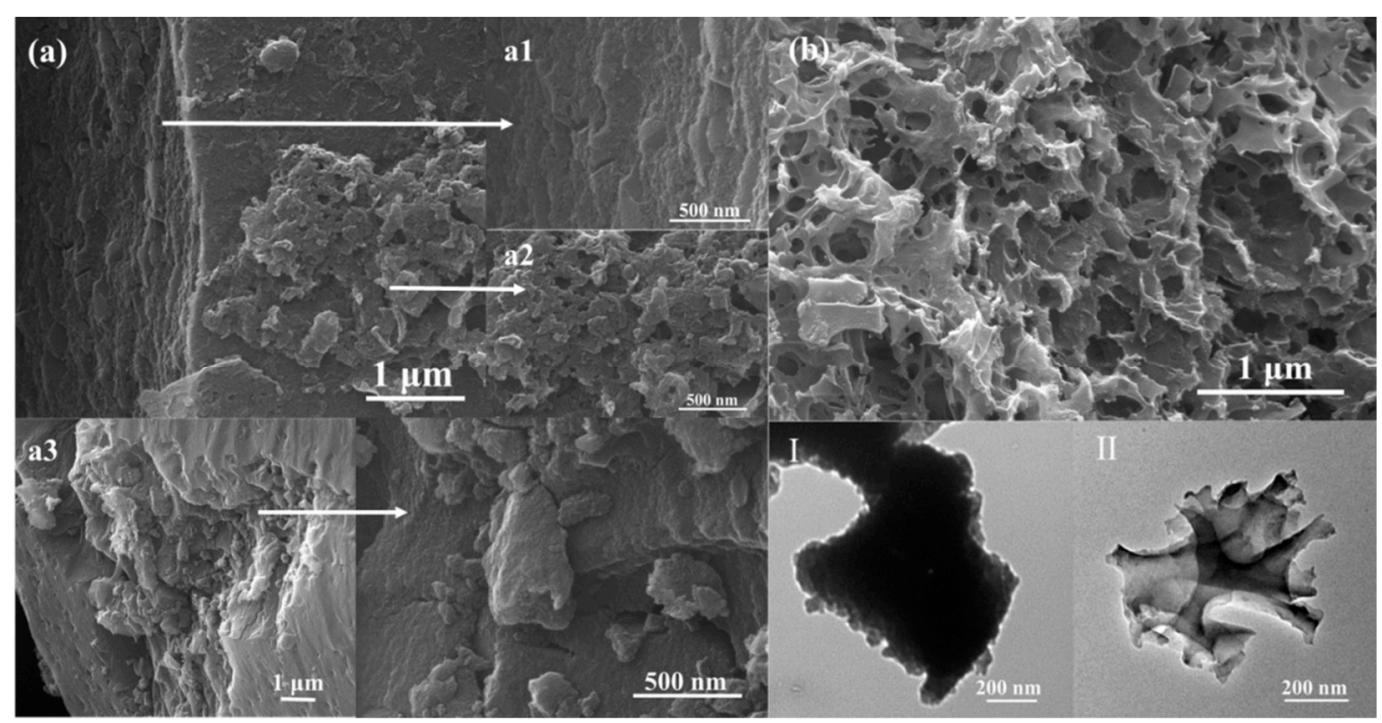

Figure 5. SEM (a-b) and TEM (I-II) images of (a) keratin-based char material (KCM)a-C; (b) KCMa-T; (I) KCMa-C; and (II) KCMa-T.

\subsection{BET Analysis}

The $\mathrm{N}_{2}$ adsorption-desorption isotherms and the corresponding pore size distribution curves of biochars, which were prepared under different atmospheres, were used to analyze the porous structure and specific surface area. In Figure 6, similar type IV absorption and desorption isotherms along with an $\mathrm{H} 4$ hysteresis curve [32] appear for CCMa-N $2, \mathrm{CCMa}-$ Ar, KCMa-C, KCMc-T, and KCMa-T. This indicates that the accumulated particles form slit pores, which produce mesoporous structures in biochar [33]. The specific surface area of CCMa-N 2 and CCMa-Ar reaches 1753.075 and $1730.93 \mathrm{~m}^{2} / \mathrm{g}$ (Table S1), respectively, representing that the $\mathrm{KOH}$ activation increases the specific surface area effectively. The specific surface area of KCMa-C is $1409.016 \mathrm{~m}^{2} / \mathrm{g}$. Though the $\mathrm{MgO}$ template method can make the biochar structure more orderly, the specific surface area is not improved. This is because $\mathrm{MgO}$ forms a large number of macroporous structures, and the increasing pore volume leads to a decrease in the specific surface area of KCMc-T (Figure 5). By observing the pore diameter distribution, the diameters of CCMs and KCMs were found to mainly be in the range of 2-20 nm, which presents the appearance of a large number of mesopores [34]. The unique porous structure and high specific surface area of biochar may result in an abundance of applications, such as adsorption materials [35] and electrode materials [36], in the future. 


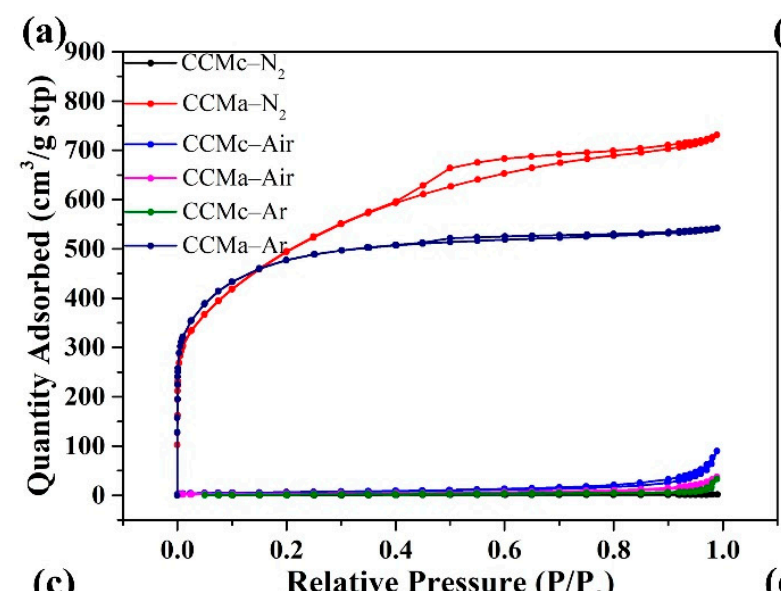

(b)

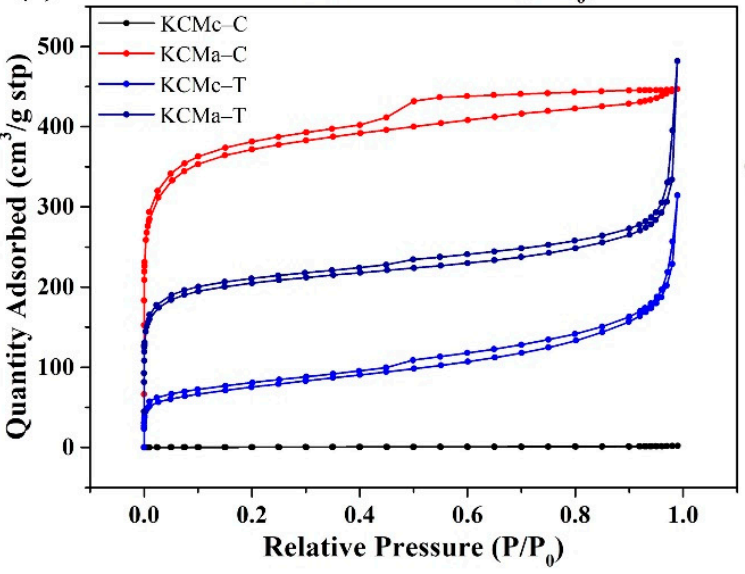

(d)
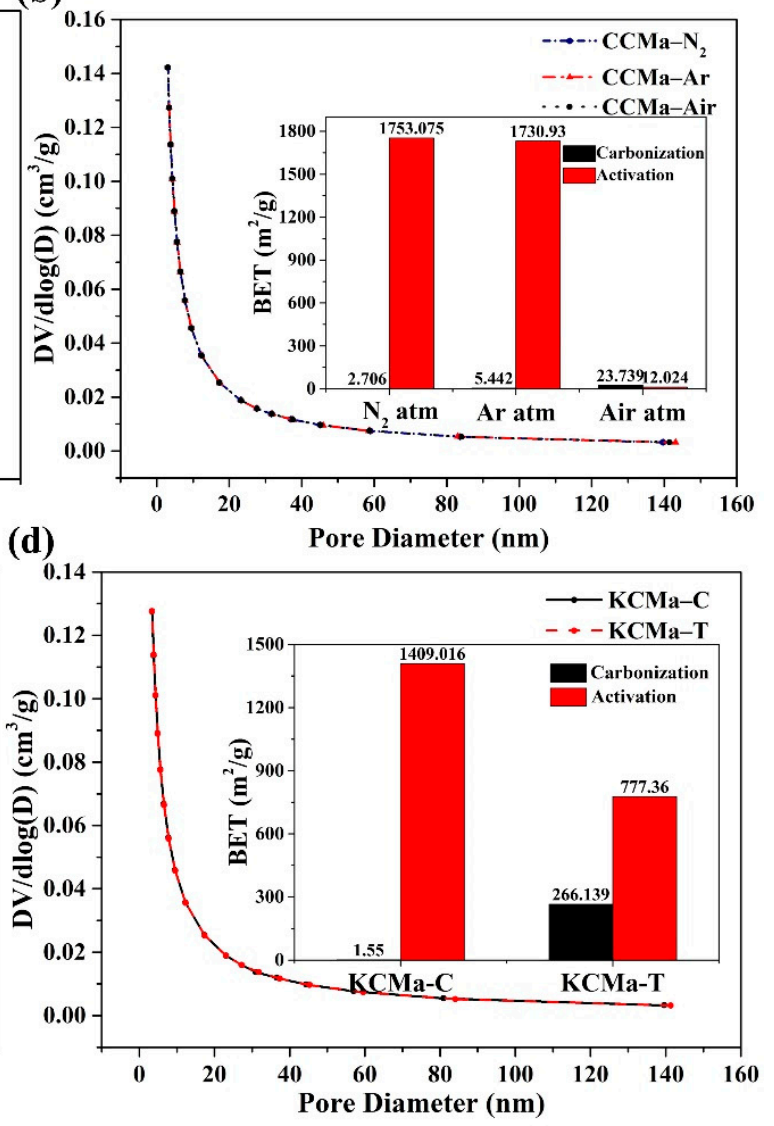

Figure 6. (a) $\mathrm{N}_{2}$ adsorption-desorption isotherm of CCMs; (b) Pore size distribution curves of CCMs; (c) $\mathrm{N}_{2}$ adsorptiondesorption isotherm of KCMs and (d) Pore size distribution curves and Brunauer-Emmett-Teller (BET) values of KCMs.

\subsection{Characterization \\ 3.6.1. XPS Analysis}

Figure 7a-c displays the XPS spectra of CCMa- $\mathrm{N}_{2}, \mathrm{CCMa}-\mathrm{Ar}$, and CCMa-Air. In the $\mathrm{C} 1 \mathrm{~s}$ spectra of $\mathrm{CCMa}-\mathrm{N}_{2}$ (Figure 7a), the dominant peaks at 284.38, 284.78, 285.99, and 289.75 are attributed to $\mathrm{C}-\mathrm{C} / \mathrm{C}=\mathrm{C}, \mathrm{C}-\mathrm{O} / \mathrm{C}-\mathrm{N}, \mathrm{C}=\mathrm{O}$, and $\mathrm{O}-\mathrm{C}=\mathrm{O}$, respectively [37]. The $\mathrm{C}-\mathrm{C} / \mathrm{C}=\mathrm{C}$ peak intensity of $\mathrm{CCMa}-\mathrm{Ar}$ (Figure $7 \mathrm{~b}$ ) decreases to $283.7 \mathrm{eV}$, whereas the $\mathrm{C}-$ $\mathrm{O} / \mathrm{C}-\mathrm{N}$ peak intensity is at $284.8 \mathrm{eV}$. This suggests the dehydrogenation of keratin and the formation of $\mathrm{O}$-doped CCMa- $\mathrm{N}_{2}$ under the $\mathrm{N}_{2}$ atmosphere. From the $\mathrm{C} 1 \mathrm{~s}$ peaks of CCMaAir (Figure 7c), the signals at $292.72 \mathrm{eV}$ and $295.47 \mathrm{eV}$ should be assigned to $\pi$ and $\sigma$ electron delocalization, respectively [38]. The increased $\mathrm{C}=\mathrm{O}$ peak intensity and the disappearance of $\mathrm{O}-\mathrm{C}=\mathrm{O}$ are due to the reaction between the cow hair and the oxygen in the air. From the $\mathrm{C} 1 \mathrm{~s}$ spectra of $\mathrm{KCMa}-\mathrm{C}$ (Figure 7d) and $\mathrm{KCMa}-\mathrm{T}$ (Figure 7e), the peaks around at 284, 284.4, 286, and $288.5 \mathrm{eV}$ represent $\mathrm{C}-\mathrm{C} / \mathrm{C}=\mathrm{C}, \mathrm{C}-\mathrm{O} / \mathrm{C}-\mathrm{N}, \mathrm{C}=\mathrm{O}$, and $\mathrm{O}-\mathrm{C}=\mathrm{O}$, respectively. Therefore, the amounts of amides and hydrogen-containing functional groups decrease, and a number of oxygen-containing functional groups remain in the biochar in the $\mathrm{N}_{2}$ and Ar atmospheres (Figure S2). The oxygen content of biochar is significant in application, and it has been confirmed that oxygen-containing functional groups have important effects on the absorption of mercury [39] and the capacitive properties of biochars [40]. 

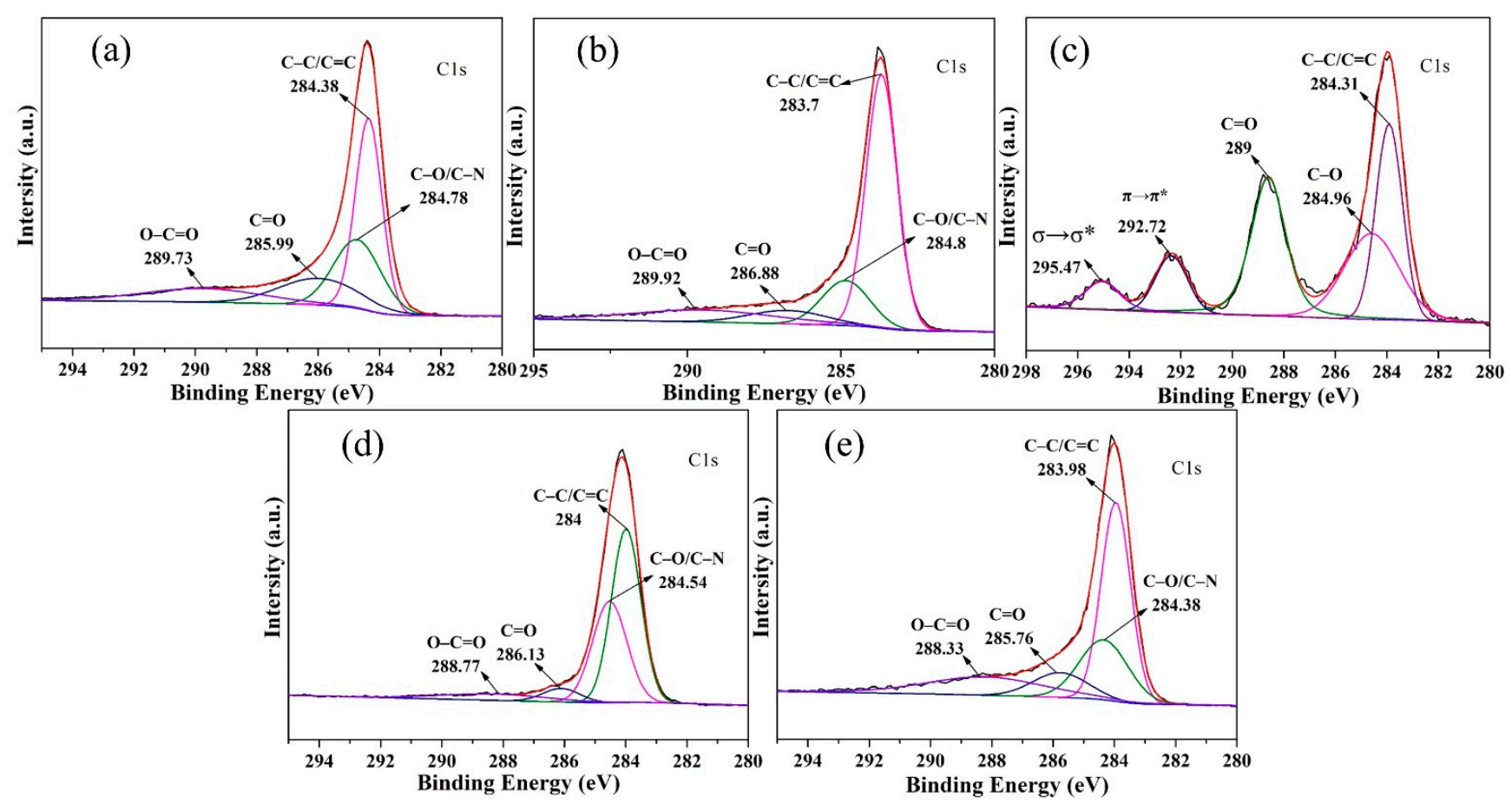

Figure 7. XPS spectra (C1s) of (a) CCMa-N 2 ; (b) CCMa-Ar; (c) CCMa-Air; (d) KCMa-C and (e) KCMa-T.

\subsubsection{XRD and Raman analysis}

The XRD spectra of CCMs and KCMs are displayed in Figure 8a, which shows an amorphous structure. CCMa-Air has a wide diffraction peak at $21^{\circ}$, reflecting the presence of amorphous or disordered carbon [41]. In the spectra of CCMs, the diffraction peaks appear at 23 and $43^{\circ}$, corresponding to the (002) (parallel graphite flake accumulation) and (100) lattice planes of graphite, respectively [42]. This indicates the formation of sp2 hybrid carbon, which reflects that these chars contain single-layer carbon sheet structures. The wide peaks at 23 and $43^{\circ}$ in CCMa- $\mathrm{N}_{2}, \mathrm{CCMa}-\mathrm{Ar}$, and CCMa-Air represent the existence of amorphous carbon. The peaks of CCM at 29.4 and $36^{\circ}$ indicate the 110 and 111 lattice planes of carbon, respectively [43]. In addition, the peaks of CCM at 39.5, 47.5, 48.5, and $57.5^{\circ}$ represent the crystal phases of the different keratin-based biochars. The diffraction peaks at 39.5, 47.5, 48.5, and 57.5 correspond to the Bragg reflection planes of 107, 206, 304, and 314, respectively [44]. Both KCMa-C and KCMa-T have a wide diffraction peak in the range of $20-30^{\circ}$. This indicates that $\mathrm{KCMa}-\mathrm{C}$ and $\mathrm{KCMa}-\mathrm{T}$ are disordered graphite carbon. The wide diffraction peak of $\mathrm{KCMa}-\mathrm{C}$ at $44^{\circ}$ further proves the amorphous structure [45].
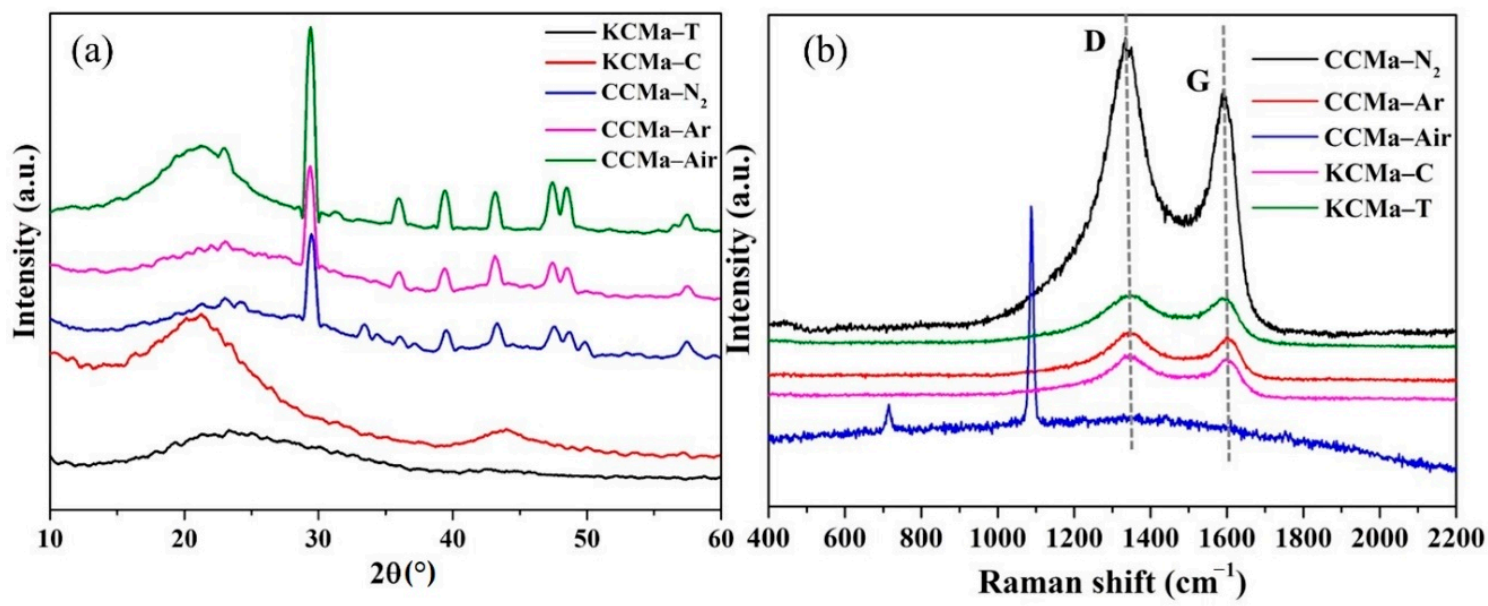

Figure 8. (a) XRD spectra and (b) Raman spectra. 
Figure $8 \mathrm{~b}$ shows the Raman spectra of CCMs and KCMs. The peaks of the G band and $\mathrm{D}$ band of these biochars are exhibited at $1343 \mathrm{~cm}^{-1}$ and $1603 \mathrm{~cm}^{-1}$. The D-band represents the low symmetry or irregularity of carbon materials, while the G-band is generated by the stretching vibration of sp2 hybrid atoms in the sample, indicating the presence of ordered graphitized carbon [46]. The intensity ratio of the D-band to the G-band (ID/IG) indicates the graphitization degree of carbon [47]. The ID/IG of CCMa- $\mathrm{N}_{2}$ and CCMa-Ar is 1.11 and 1.028, respectively. This indicates that the graphitization degree of $C C M a-\mathrm{N}_{2}$ is lower than that of CCMa-Ar. The CCMa-Air does not have a graphitized structure [48] because the presence of $\mathrm{O}_{2}$ in air leads to a decrease in the $\mathrm{C}$ content in the final biochar. The new peaks around 700 and $1100 \mathrm{~cm}^{-1}$ of CCMa-Air are attributed to the residual calcium [49]. In addition, the ID/IG of KCMa-C and KCMa-T is 1.027 and 1.017, respectively. This indicates that the graphitization degree of $\mathrm{KCMa}-\mathrm{T}$ is successfully improved by the $\mathrm{MgO}$ template method.

\subsection{Adsorption and Regeneration Experiments}

The results show that the adsorption capacity of CCMa- $\mathrm{N}_{2}$ to DB dye reaches $1477 \mathrm{mg} / \mathrm{g}$ in $50 \mathrm{~g} / \mathrm{L}$ of DB solution, while the adsorption capacity of AC is $928 \mathrm{mg} / \mathrm{g}$. Thereby, the CCMa- $\mathrm{N}_{2}$ shows a higher adsorption capacity with a high concentration of wastewater. When the DB concentration has a low concentration (below $40 \mathrm{~g} / \mathrm{L}$ ), the adsorption capacity is low, which should result in the special bread-like structure. The compacted shell of biochar prevents the penetration of dye molecules as shown in Figure 9c. Compared to CCMa- $\mathrm{N}_{2}$, the structure of AC is open-type, which can take the physical adsorption with the dye in wastewater sufficiently at low concentrations [50]. The adsorption capacity of AC can reach $932 \mathrm{mg} / \mathrm{g}$ in $40 \mathrm{~g} / \mathrm{L}$ of DB solution, while that of CCMa- $\mathrm{N}_{2}$ is $739 \mathrm{mg} / \mathrm{g}$. With the increase in the dye concentration in solution, the osmotic pressure is improved. The high driving force causes a large amount of dye molecules to penetrate through the compacted shell [51], while the compacted shell prevents the spread of dye molecules in solution. Thus, the dye molecules can be adsorbed onto the surface of the compacted shell as well as in the spongy interior (Figure 9c). In the saturated solution of the DB dye, the adsorption capacity reaches $3670 \mathrm{mg} / \mathrm{g}$ (Figure 9a), which is higher than that of AC $(2466 \mathrm{mg} / \mathrm{g})$. In addition, the desorption of dye and the regeneration adsorption of biochar are significant as shown in Figure $9 \mathrm{~b}$. In five cycles, the absorption ability of CCMa- $\mathrm{N}_{2}$ is stable at around $1500 \mathrm{mg} / \mathrm{g}$. In summary, the keratin-based biochars display a positive ability to adsorb dye, and they can be expected to be used for further heavy metal adsorption with a high concentration. 
(a)

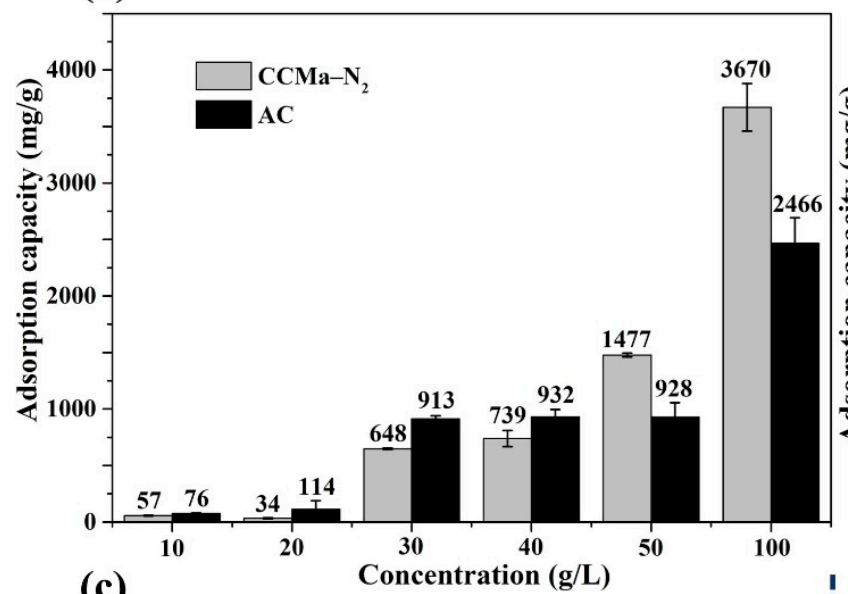

(c) (b)

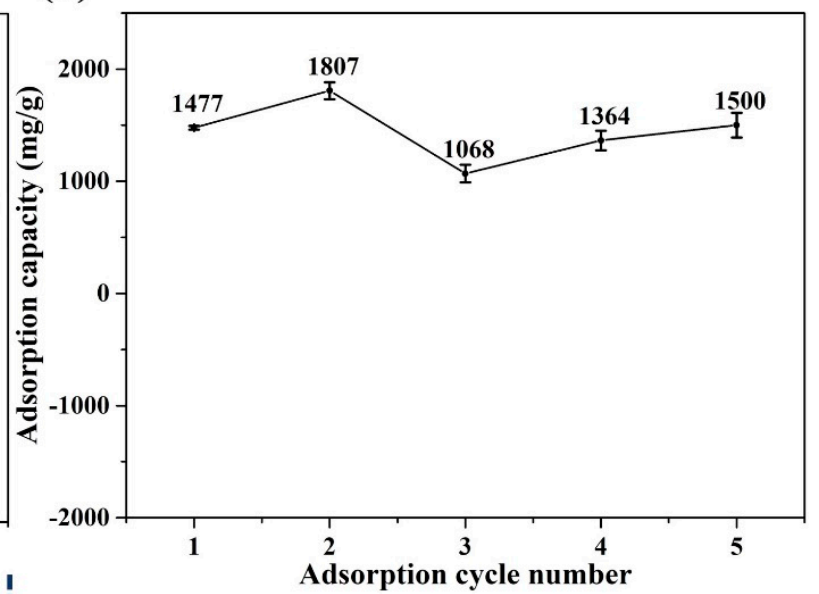

High concentration

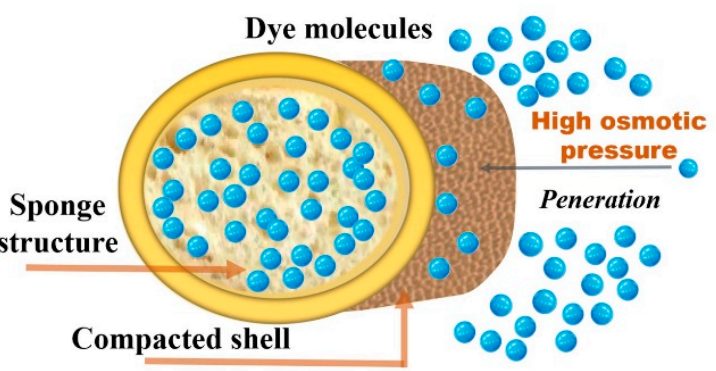

Figure 9. Adsorption and regeneration. (a) The adsorption capacity analysis; (b) The regeneration capacity in $50 \mathrm{~g} / \mathrm{L}$ of direct blue (DB) dye solution; (c) The adsorption mechanism diagram.

\section{Conclusions}

In this study, cow hair waste was used to prepare porous biochar due to the integral structure and high carbon content. The formation mechanism of biochar based on hair waste was analyzed under different atmospheres. The porous biochars including CCMa$\mathrm{N}_{2}$ and CCMa-Ar have a similar and complex bread-like structure and a high degree of graphitization. The specific surface area of CCMa- $\mathrm{N}_{2}$ reaches $1753.075 \mathrm{~m}^{2} / \mathrm{g}$. The KCMa$\mathrm{T}$, which was generated by the $\mathrm{MgO}$ template method, has an orderly sponge structure with a large number of mesopores, and has the highest graphitization degree (ID/IG $=1.017$ ). The purified keratin extracted from the hair waste leads to the simple structure of KCMa-T and KCMa-C, and the specific surface area of KCMa-C is $1409.016 \mathrm{~m}^{2} / \mathrm{g}$. The CCMa$\mathrm{N}_{2}$ is effective for DB dye adsorption and its adsorption ability in $50 \mathrm{~g} / \mathrm{L}$ of DB dye solution $(1477 \mathrm{mg} / \mathrm{g})$ is better than that of activated carbon $(928 \mathrm{mg} / \mathrm{g})$. In five cycles of regeneration, the adsorption ability was found to be stable at approximately $1500 \mathrm{mg} / \mathrm{g}$. This study proposes a novel method to deal with the cow hair solid waste produced by the leather industry and provides a highly efficient adsorbent for further applications.

Supplementary Materials: The following are available online at https://www.mdpi.com/article/10 $.3390 / \mathrm{ma14071690/s1}$, Table S1: The BET of biochars. Figure S1: XPS spectra of (a) CCMa-N ${ }_{2}$ (b) CCMa-Ar, (c) CCMa-Air, (d) KCMa-C, and (e) KCMa-T. Figure S2: FTIR spectra of (a) CCMs and (b) KCMs. 
Author Contributions: Conceptualization, S.C.; Formal Analysis, J.S., Y.W. and Y.L. (Yang Liu); Investigation, J.S., Y.L. (Yun Li) and Y.W.; Validation, Y.L. (Yun Li), X.S. and B.H.; Resources, S.C. and Y.L. (Yanchun Li); Data Curation, L.Z., Y.L. (Yang Liu), X.S., and B.H.; Writing-Original Draft Preparation, J.S.; Writing-Review \& Editing, S.C. and Y.L. (Yanchun Li); Supervision, S.C. and Y.L. (Yanchun Li); Project Administration, S.C. and Y.L. (Yanchun Li). All authors have read and agreed to the published version of the manuscript.

Funding: This research was funded by the National Natural Science Foundation of China (No.21808170), the National Key Research and Development Program of China (2017YFB0308401), the Shandong Provincial Natural Science Foundation, China (ZR2019BB081).

Institutional Review Board Statement: Not applicable.

Informed Consent Statement: Not applicable.

Data Availability Statement: Data is contained within the article.

Acknowledgments: The authors thank Xiu He at the College of Biomass Science and Engineering, Sichuan University, for experimental assistance.

Conflicts of Interest: The authors declare no conflict of interest.

$\begin{array}{ll}\text { Abbreviations } & \\ \text { Full Name } & \text { Abbreviation } \\ \text { Cowhair-based char material-carbonization } & \text { CCMc } \\ \text { Cowhair-based char material-activation } & \text { CCMa } \\ \text { Keratin-based char material-carbonation } & \text { KCMc } \\ \text { Keratin-based char material-activation } & \text { KCMa }\end{array}$

\section{References}

1. Zhang, Y.; Zhang, B.; Shan, Z. Preparation of sound-insulating material based on discarded cow hair. J. Appl. Polym. Sci. 2018, 135, 46332. [CrossRef]

2. Shavandi, A.; Silva, T.H.; Bekhit, A.A.; Bekhit, A.E.D.A. Keratin: Dissolution, extraction and biomedical application. Biomater. Sci. 2017, 5, 1699-1735. [CrossRef]

3. Abbas, Q.; Liu, G.; Yousaf, B.; Ali, M.U.; Ullah, H.; Munir, M.A.M.; Liu, R. Contrasting effects of operating conditions and biomass particle size on bulk characteristics and surface chemistry of rice husk derived-biochars. J. Anal. Appl. Pyrolysis 2018, 134, 281-292. [CrossRef]

4. $\quad \mathrm{Li}, \mathrm{H} . ; \mathrm{Hu}$, J.; Meng, Y.; Su, J.; Wang, X. An investigation into the rapid removal of tetracycline using multilayered graphene-phase biochar derived from waste chicken feather. Sci. Total Environ. 2017, 603-604, 39-48. [CrossRef]

5. Ou, J.; Zhang, Y.; Chen, L.; Zhao, Q.; Meng, Y.; Guo, Y.; Xiao, D. Nitrogen-rich porous carbon derived from biomass as a high performance anode material for lithium ion batteries. J. Mater. Chem. A 2015, 3, 6534-6541. [CrossRef]

6. Tang, L.; Zhou, Y.; Zhou, X.; Chai, Y.; Zheng, Q.; Lin, D. Enhancement in electrochemical performance of nitrogen-doped hierarchical porous carbon-based supercapacitor by optimizing activation temperature. J. Mater. Sci. Mater. Electron. 2019, 30, 2600-2609. [CrossRef]

7. Januszewicz, K.; Kazimierski, P.; Klein, M.; Kardaś, D.; Łuczak, J. Activated Carbon Produced by Pyrolysis of Waste Wood and Straw for Potential Wastewater Adsorption. Materials 2020, 13, 2047. [CrossRef] [PubMed]

8. Chaithra, K.P.; Bhat, V.S.; Maiyalagan, T.; Hegde, G.; Varghese, A.; George, L. Unique Host Matrix to Disperse Pd Nanoparticles for Electrochemical Sensing of Morin: Sustainable Engineering Approach. ACS Biomater. Sci. Eng. 2020, 6, 5264-5273. [CrossRef]

9. Li, M.; Li, Y.W.; Yu, X.L.; Guo, J.J.; Xiang, L.; Liu, B.L.; Zhao, H.M.; Xu, M.Y.; Feng, N.X.; Yu, P.F.; et al. Improved bio-electricity production in bio-electrochemical reactor for wastewater treatment using biomass carbon derived from sludge supported carbon felt anode. Sci. Total Environ. 2020, 726, 138573. [CrossRef]

10. Ren, J.; Zhou, Y.; Wu, H.; Xie, F.; Xu, C.; Lin, D. Sulfur-encapsulated in heteroatom-doped hierarchical porous carbon derived from goat hair for high performance lithium-sulfur batteries. J. Energy Chem. 2019, 30, 121-131. [CrossRef]

11. Kim, P.; Johnson, A.; Edmunds, C.W.; Radosevich, M.; Vogt, F.; Rials, T.G.; Labbé, N. Surface functionality and carbon structures in lignocellulosic-derived biochars produced by fast pyrolysis. Energy Fuels 2011, 25, 4693-4703. [CrossRef]

12. Wang, B.; Yang, W.; McKittrick, J.; Meyers, M.A. Keratin: Structure, mechanical properties, occurrence in biological organisms, and efforts at bioinspiration. Prog. Mater. Sci. 2016, 76, 229-318. [CrossRef]

13. Singh, S.K.; Prakash, H.; Akhtar, M.J.; Kar, K.K. Lightweight and high performance microwave absorbing heteroatom doped carbon derived from chicken featherfibers. ACS Sustain. Chem. Eng. 2018, 6, 5381-5393. [CrossRef] 
14. Saravanan, K.; Kalaiselvi, N. Nitrogen containing bio-carbon as a potential anode for lithium batteries. Carbon 2015, 81, 43-53. [CrossRef]

15. Li, Y.; Xu, R.; Wang, B.; Wei, J.; Wang, L.; Shen, M.; Yang, J. Enhanced N-doped porous carbon derived from KOH-activated waste wool: A promising material for selective adsorption of $\mathrm{CO}_{2} / \mathrm{CH}_{4}$ and $\mathrm{CH}_{4} / \mathrm{N}_{2}$. Nanomaterials 2019, 9, 266. [CrossRef]

16. Sun, Q.; Jiang, T.; Zhao, G.; Shi, J. Porous Carbon Material based on Biomass Prepared by $\mathrm{MgO} \mathrm{Template} \mathrm{Method} \mathrm{and} \mathrm{ZnCl}_{2}$ Activation Method as Electrode for High Performance Supercapacitor. Int. J. Electrochem. Sci. 2019, 14, 1-14. [CrossRef]

17. Kumar, A.; Jena, H.M. Preparation and characterization of high surface area activated carbon from Fox nut (Euryale ferox) shell by chemical activation with $\mathrm{H}_{3} \mathrm{PO}_{4}$. Results Phys. 2016, 6, 651-658. [CrossRef]

18. Wu, C.; Yan, P.; Zhang, R.; Jin, J.; Zhang, X.; Kang, H. Comparative study of $\mathrm{HNO}_{3}$ activation effect on porous carbons having different porous characteristics. J. Appl. Electrochem. 2015, 45, 849-856. [CrossRef]

19. Tyagi, A.; Banerjee, S.; Singh, S.; Kar, K.K. Biowaste derived activated carbon electrocatalyst for oxygen reduction reaction: Effect of chemical activation. Int. J. Hydrog. Energy 2020, 45, 16930-16943. [CrossRef]

20. Xu, Z.; Chen, J.; Wu, M.; Chen, C.; Song, Y.; Wang, Y. Effects of Different Atmosphere on Electrochemical Performance of Hard Carbon Electrode in Sodium Ion Battery. Electron. Mater. Lett. 2019, 15, 428-436. [CrossRef]

21. Tan, X.F.; Liu, Y.G.; Gu, Y.L.; Xu, Y.; Zeng, G.M.; Hu, X.J.; Liu, S.B.; Wang, X.; Liu, S.M.; Li, J. Biochar-based nano-composites for the decontamination of wastewater: A review. Bioresour. Technol. 2016, 212, 318-333. [CrossRef] [PubMed]

22. Cao, S.; Li, D.; Ma, X.; Xin, Q.; Li, Y. A novel unhairing enzyme produced by heterologous expression of keratinase gene (kerT) in Bacillus subtilis. World J. Microbiol. Biotechnol. 2019, 35, 122. [CrossRef]

23. Zhu, C.; Akiyama, T. Cotton derived porous carbon via an $\mathrm{MgO}$ template method for high performance lithium ion battery anodes. Green Chem. 2016, 18, 2106-2114. [CrossRef]

24. Wang, C.; Wu, D.; Wang, H.; Gao, Z.; Xu, F.; Jiang, K. A green and scalable route to yield porous carbon sheets from biomass for supercapacitors with high capacity. J. Mater. Chem. A 2018, 6, 1244-1254. [CrossRef]

25. Gao, Q.; Liu, H.; Cheng, C.; Li, K.; Zhang, J.; Zhang, C.; Li, Y. Preparation and characterization of activated carbon from wool waste and the comparison of muffle furnace and microwave heating methods. Powder Technol. 2013, 249, 234-240. [CrossRef]

26. Wang, Y.; Rong, Z.; Tang, X.; Cao, S.; Chen, X.; Dang, W.; Wu, L. The design of scorodite@FeOOH core-shell materials and its stability treatment for arsenide. Appl. Surf. Sci. 2019, 496, 143719. [CrossRef]

27. Piccin, J.S.; Gomes, C.S.; Feris, L.A.; Gutterres, M. Kinetics and isotherms of leather dye adsorption by tannery solid waste. Chem. Eng. J. 2012, 183, 30-38. [CrossRef]

28. Murcia-Salvador, A.; Pellicer, J.A.; Fortea, M.I.; Gómez-López, V.M.; Rodríguez-López, M.I.; Núñez-Delicado, E.; Gabaldón, J.A. Adsorption of Direct Blue 78 using chitosan and cyclodextrins as adsorbents. Polymers 2019, 11, 1003. [CrossRef]

29. Zhang, G.; Chen, Y.; Chen, Y.; Guo, H. Activated biomass carbon made from bamboo as electrode material for supercapacitors. Mater. Res. Bull. 2018, 102, 391-398. [CrossRef]

30. Wang, J.; Kaskel, S. KOH activation of carbon-based materials for energy storage. J. Mater. Chem. 2012, 22, 23710-23725. [CrossRef]

31. Sun, J.; Niu, J.; Liu, M.; Ji, J.; Dou, M.; Wang, F. Biomass-derived nitrogen-doped porous carbons with tailored hierarchical porosity and high specific surface area for high energy and power density supercapacitors. Appl. Surf. Sci. 2018, 427, 807-813. [CrossRef]

32. Machado, L.M.M.; Lütke, S.; Perondi, D.; Godinho, M.O.; Oliveira, M.L.S.; Collazzo, G.; Dotto, G.L. Treatment of effluents containing 2-chlorophenol by adsorption onto chemically and physically activated biochars. J. Environ. Chem. Eng. 2020, 8, 104473. [CrossRef]

33. Tanhaei, M.; Mahjoub, A.R.; Safarifard, V. Energy-efficient sonochemical approach for preparation of nanohybrid composites from graphene oxide and metal-organic framework. Inorg. Chem. Commun. 2019, 102, 185-191. [CrossRef]

34. Cao, S.; Song, J.; Li, H.; Wang, K.; Li, Y.; Li, Y.; Lu, F.; Liu, B. Improving characteristics of biochar produced from collagencontaining solid wastes based on protease application in leather production. Waste Manag. 2020, 105, 531-539. [CrossRef] [PubMed]

35. Senoz, E.; Wool, R.P. Microporous carbon-nitrogen fibers from keratin fibers by pyrolysis. J. Appl. Polym. Sci. 2010, 118, 1752-1765. [CrossRef]

36. Hu, Y.S.; Adelhelm, P.; Smarsly, B.M.; Hore, S.; Antonietti, M.; Maier, J. Synthesis of hierarchically porous carbon monoliths with highly ordered microstructure and their application in rechargeable lithium batteries with high-rate capability. Adv. Funct. Mater. 2007, 17, 1873-1878. [CrossRef]

37. Wang, T.; Liu, H.; Duan, C.; Xu, R.; Zhang, Z.; She, D.; Zheng, J. The Eco-Friendly Biochar and Valuable Bio-Oil from Caragana korshinskii: Pyrolysis Preparation, Characterization, and Adsorption Applications. Materials 2020, 13, 3391. [CrossRef]

38. Gong, Y.; Li, D.; Luo, C.; Fu, Q.; Pan, C. Highly porous graphitic biomass carbon as advanced electrode materials for supercapacitors. Green Chem. 2017, 19, 4132-4140. [CrossRef]

39. Zhang, B.; Xu, P.; Qiu, Y.; Yu, Q.; Ma, J.; Wu, H.; Luo, G.; Xu, M.; Yao, H. Increasing oxygen functional groups of activated carbon with non-thermal plasma to enhance mercury removal efficiency for flue gases. Chem. Eng. J. 2015, 263, 1-8. [CrossRef]

40. Liang, Z.; Xia, H.; Liu, H.; Zhang, L.; Zhou, J.; Li, H.; Xie, W. Enhanced capacitance characteristic of microporous carbon spheres through surface modification by oxygen-containing groups. Results Phys. 2019, 15, 102586. [CrossRef]

41. Zhao, Y.; Lu, M.; Tao, P.; Zhang, Y.; Gong, X.; Yang, Z.; Zhang, G.; Li, H. Hierarchically porous and heteroatom doped carbon derived from tobacco rods for supercapacitors. J. Power Sources 2016, 307, 391-400. [CrossRef] 
42. Zhao, C.; Zhong, S.; Li, C.; Zhou, H.; Zhang, S. Property and mechanism of phenol degradation by biochar activated persulfate. J. Mater. Res. Technol. 2020, 9, 601-609. [CrossRef]

43. Chandra, S.; Das, P.; Bag, S.; Laha, D.; Pramanik, P. Synthesis, functionalization and bioimaging applications of highly fluorescent carbon nanoparticles. Nanoscale 2011, 3, 1533-1540. [CrossRef]

44. Ahmad, A.; Jini, D.; Aravind, M.; Parvathiraja, C.; Ali, R.; Kiyani, M.Z.; Alothman, A. A novel study on synthesis of egg shell based activated carbon for degradation of methylene blue via photocatalysis. Arab. J. Chem. 2020, 13, 8717-8722. [CrossRef]

45. Prithi, J.A.; Rajalakshmi, N.; Rao, G.R. Nitrogen doped mesoporous carbon supported Pt electrocatalyst for oxygen reduction reaction in proton exchange membrane fuel cells. Int. J. Hydrog. Energy 2017, 43, 4716-4725. [CrossRef]

46. Yang, X.; Xiang, C.; Zou, Y.; Fen, X.; Mao, X.; Xuebu, H.; Zhang, J.; Sun, L. $\mathrm{NiCo}_{2} \mathrm{~S}_{4}$ on yeast-templated porous hollow carbon spheres for supercapacitors. J. Mater. Res. Technol. 2020, 9, 13718-13728. [CrossRef]

47. Ding, W.; Wu, X.; Li, Y.; Wang, S.; Zhuo, S. Nickel-Embedded Carbon Materials Derived from Wheat Flour for Li-Ion Storage. Materials 2020, 13, 4611. [CrossRef] [PubMed]

48. Xiao, P.W.; Meng, Q.; Zhao, L.; Li, J.J.; Wei, Z.; Han, B.H. Biomass-derived flexible porous carbon materials and their applications in supercapacitor and gas adsorption. Mater. Des. 2017, 129, 164-172. [CrossRef]

49. Schmid, T.; Dariz, P. Shedding light onto the spectra of lime: Raman and luminescence bands of $\mathrm{CaO}, \mathrm{Ca}(\mathrm{OH})_{2}$ and CaCO $3 . J$. Raman. Spectrosc. 2014, 46, 141-146. [CrossRef]

50. Yagub, M.T.; Sen, T.K.; Afroze, S.; Ang, H.M. Dye and its removal from aqueous solution by adsorption: A review. Adv. Colloid Interface Sci. 2014, 209, 172-184. [CrossRef]

51. Bulut, Y.; Aydın, H. A kinetics and thermodynamics study of methylene blue adsorption on wheat shells. Desalination 2006, 194, 259-267. [CrossRef] 